\title{
Análise Sociolinguistica de \\ Interferências Fonético-Fonológicas no \\ Português Brasileiro de Contato
}

Sociolinguistic Analysis of Phonetic-Phonological Interference in Brazilian Portuguese of Contact

\section{Maria Youssef ABREU *}

Resumo: O contato de línguas produz inevitáveis situações de interferência, permitindo que uma língua infiltre formas/estruturas no interior da outra. Com o fluxo imigratório ocorrido no início do século $\mathrm{XX}$, levas de imigrantes libaneses adentraram o Brasil, efetivando um reencontro na história do contato entre o árabe e o português brasileiro. O propósito central desse artigo é analisar as interferências fonéticofonológicas do português brasileiro falado por imigrantes libaneses em situação de contato na cidade de Londrina - Paraná, contemplandoas sob uma perspectiva Contrastiva e Sociolinguística. O corpus constituise da fala de dezesseis falantes bilíngues, divididos em dois grupos religiosos, cristãos e muçulmanos, sendo esses, de sexo masculino e feminino, distribuídos em dois níveis de escolaridade, $1^{\circ}$ e $2^{\circ}$ graus. A análise demonstrou que as interferências devem-se à distância entre os dois sistemas fonético-fonológicos, à ausência de aprendizado formal do português e ao status do árabe como língua de cultura e religião. Palavras-chave: Línguas em Contato; Interferência; Sociolinguística.

Abstract: The contact languages produces inevitable interference situations, allowing a language infiltrate forms/structures inside the other. With the flow of immigrants occurred in the early twentieth

* Doutoranda em Estudos da Linguagem pela Universidade Estadual de Londrina. Mestre em Estudos da Linguagem pela UEL (2005). Contato: mariaayoussef@hotmail.com 
century, waves of Lebanese immigrants entered Brazil, establishing a new stage in the history of contact between Arabic and Brazilian languages. The main purpose of this paper is to analyze the phoneticphonological interference from Brazilian Portuguese spoken by Lebanese immigrants in contact situations in the city of Londrina, Paraná, contemplating them from a perspective and Contrastive Sociolinguistics. The corpus is made up of sixteen speech bilingual speakers, divided into two religious groups, Christians and Muslims, and these, male and female, divided into two levels of schooling, 1 st and 2 nd degrees. The analysis showed that the interferences are due to the linguistic distance between the two phonetic-phonological systems, the absence of formal learning Portuguese and the status of Arabic as a language of culture and religion.

Key-word: Languages in Contact; Interference; Sociolinguistics.

\section{Introdução}

Os sistemas linguísticos não surgem num espaço abstrato, porém, desenvolvem-se na materialidade do contato estabelecido entre indivíduos e populações. Desde a divulgação de Weinreich (1974), Languages in contact, obra tradicionalmente considerada como marco inicial do estudo de fenômenos originados do contato linguístico, o estudo da interferência alcançou grande desenvolvimento. $\mathrm{O}$ autor dedica grande atenção ao que denomina causas não estruturais ou extralinguísticas da interferência, as quais favorecem ou inibem a ação da interferência. À Weinreich (1974) se deve a importância concedida aos aspectos socioculturais do bilinguismo, como o prestígio das línguas em contato, as atitudes dos falantes diante de cada uma delas, as características do bilinguismo em diferentes subgrupos de falantes, a duração e intensidade do contato linguístico. O propósito central do autor consiste em identificar em que medida a interferência era determinada pelos fatores linguísticos das línguas em contato e em que medida derivava dos fatores extralinguísticos que entravam em cena no contato das línguas.

A noção de interferência linguística considerada neste estudo não corresponde à introduzida pela Psicologia Comportamentalista, 
segundo a qual o fenômeno é interpretado como um ato mecânico, responsável por uma transferência negativa geradora de "erros" na produção linguística dos aprendizes. Essa perspectiva foi substituída graças à visão cognitivista do fenômeno, na qual a transferência de saberes da língua materna para a estrangeira é vista como um processo natural que propicia dinamismo e reflexões criativas na comunicação em língua estrangeira (SELINKER, 1972; KELLERMANN, 1979; FAERCH; KASPER, 1987; POULISSE; BONGAETER, 1994; DURÃO, 2007). A relação entre o contato de línguas e o fenômeno de interferência também é tema visto em estudos de Silva-Corvalán (1989); Moreno Fernández (1998); Gómes Molina (2000); e Vandresen e Heye (2006), entre outros.

$\mathrm{O}$ fenômeno de interferência manifestou-se no contato entre o árabe e o português brasileiro efetivado a partir do fluxo imigratório ocorrido no início do século XX no Brasil, possibilitando um reencontro na história do contato ${ }^{1}$ entre o par de línguas. A coexistência paralela dessas línguas originou (e ainda origina) situações propícias a inevitáveis fenômenos de interferências, os quais são claramente percebidos no discurso oral produzido pelos membros das comunidades bilíngues a que pertencem.

O presente artigo expõe a análise e descrição de interferências fonético-fonológicas definidas como metaplasmos, identificados no português falado por imigrantes libaneses, ${ }^{2}$ estabelecidos na cidade de

${ }^{1}$ Conforme é amplamente divulgado, a história do contato entre as línguas começou na região da Península Ibérica. Segundo extensa bibliografia que documenta a história - entre as quais destacamos Coutinho (1976) e Silva Neto (1988) -, árabes e bérberes do Magreb adentraram o território que compreendia a Península Ibérica, conquistando grande parte dessa região. Denominados 'mouros' pelos habitantes da Península, esses povos tinham o islã como religião e o árabe como a língua de comunicação (mesmo aqueles que falavam a língua bérbere). O império árabe-muçulmano foi se consolidando nessa região por longo período, estimado, aproximadamente entre sete e oito séculos (levando-se em consideração a data de sua chegada, em 715 , até sua expulsão, no século VII).

${ }^{2}$ Nas experiências prévias com imigrantes da comunidade libanesa da cidade de Londrina-PR, verificamos que as interferências provocadas pelo árabe na 
Londrina, norte do Paraná. Os dados parciais expostos neste artigo constituem um recorte de tese, em nível de doutoramento, cujo propósito central é o estudo dos fatores linguísticos e extralinguísticos determinantes na geração de interferência no discurso oral dos falantes referidos. Para fins teórico-metodológicos, ampara-se na Sociolinguística do contato linguístico, a partir de um corpus constituído de dados da fala espontânea de dezesseis imigrantes libaneses, falantes de árabe e português, com idade superior a 18 anos, comerciantes de profissão e com permanência no país entre 20 a 45 anos. Apresentam-se divididos em dois grupos religiosos - cristãos e muçulmanos -, de sexo masculino e feminino, distribuídos em dois níveis de escolaridade fundamental e médio -, com dois informantes em cada nível. Os dados foram colhidos mediante a realização de entrevista semidirigidas, gravadas em fita cassete, com o gravador à vista do informante e, posteriormente, transcritas. O material transcrito perfaz um total de aproximadamente 1.200 minutos de gravação. As interferências foram classificadas no programa Lexico3, em cada nível gramatical, separadamente.

\section{Panorama histórico da imigração libanesa: o mascate e o mito}

De acordo com Safady (1989), a imigração libanesa aconteceu a partir das duas últimas décadas do século XIX e nas primeiras do século XX, desenvolvendo-se em um movimento característico que marcou sua trajetória no panorama mundial, quando muitos libaneses viram-se impulsionados sobretudo por pressões demográficas e econômicas em sua terra de origem. Esses fatos, entretanto, coincidiram com uma situação de conjuntura econômica e política de estímulo destinado à colonização e ao povoamento das terras brasileiras.

Knowlton (1995), o primeiro historiador da imigração libanesa, narra as aventuras e os equívocos ocorridos durante as viagens dos pioneiros libaneses para o Brasil. Esses aventureiros vieram para o

constituição do português produzido por tais falantes não eram aleatórias, mas sistemáticas. Isto é, há uma tendência uniforme por parte desses falantes em usar ou reproduzir padrões linguísticos do árabe na produção do português. 
Brasil, por não terem obtido visto para os Estados Unidos ou por não preencherem as condições mais exigentes de entrada naquele país. Para não retornarem a seu país de origem, desembarcaram no Rio de Janeiro, já que estavam em continente americano. É provável, segundo o autor, que outros tenham desembarcado no porto de Santos acreditando piamente estarem em solo norte-americano, muitas vezes enganados por agências de navegação. E, finalmente, há aqueles que vieram para o Brasil estimulados por parentes e amigos ou por acreditarem no país como o lugar adequado para fazer fortunas. Knowlton (1995) informa que famílias dos primeiros imigrantes libaneses eram numerosas e bastante unidas em torno das atividades comerciais
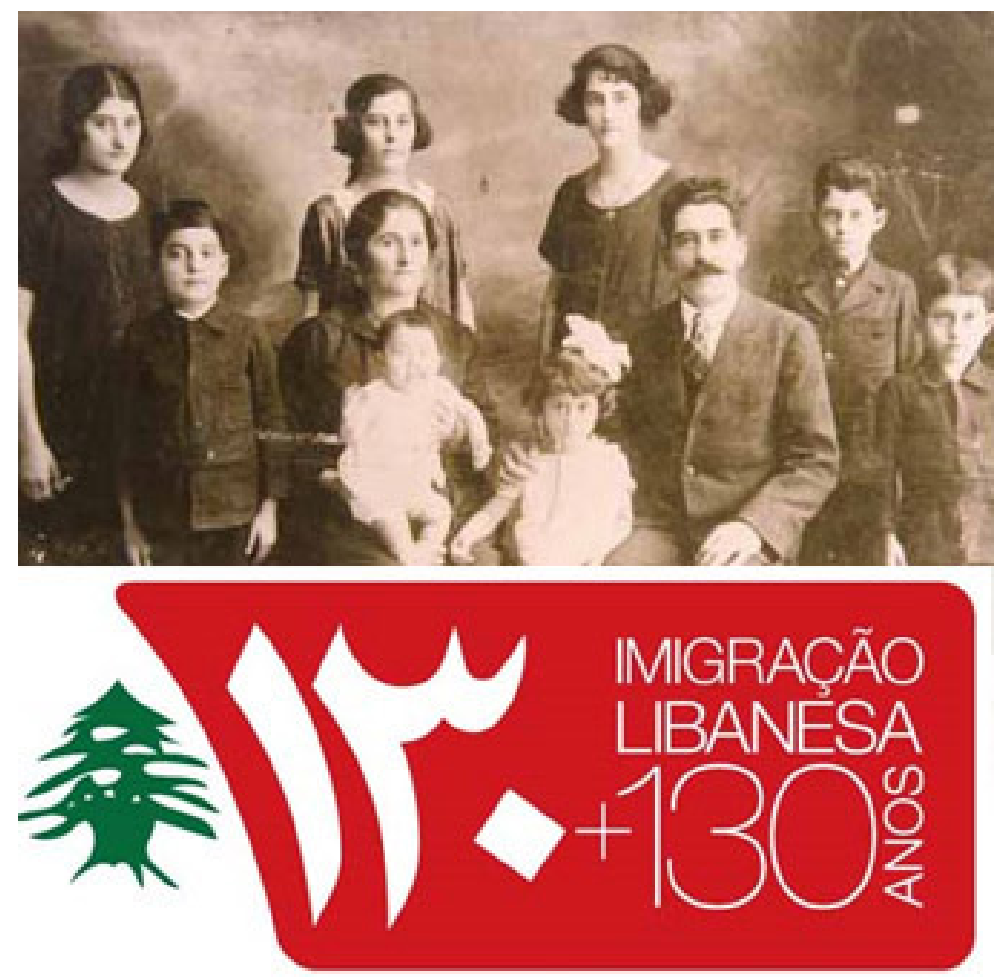

Fonte: http://www.cidadedesaopaulo.com

Figura 1 - Imagem comemorativa dos 130 anos da Imigração Libanesa no Brasil 
Ao chegarem ao Brasil, os imigrantes libaneses mostraram sua natureza versátil e sociável. Habituados a conciliar antagonismos, encontraram facilidade de integrar-se às novas situações. Dedicaramse, inicialmente, à atividade temporária da mascateação, comercializando nos campos e nas praças os diversos tipos de mercadoria. Com um 'armarinho' nas costas, os mascates carregavam toda sorte de mercadorias e miudezas - de roupas a alfinetes. Com o intenso exercício dessa atividade, adquiriram informalmente o português, muitas vezes, falando alternadamente as duas línguas, na tentativa de se fazerem compreender pelos brasileiros. Desbravaram caminhos e sertões brasileiros e, alguns anos mais tarde, o caminho natural foi a abertura de lojas, fábricas e indústrias. Estabelecendo residência ao lado das lojas e possibilitando serviços de entrega e crediário facilitado aos usuários, os membros da família possibilitavam uma mão de obra barata, com longas horas de jornada de trabalho. À medida que os negócios prosperavam, parentes e contemporâneos fomentavam um maior fluxo migratório para o país.

Para preservar os laços culturais, em determinados finais de semana e feriados, os primeiros imigrantes organizavam reuniões em piqueniques com amigos brasileiros, patrícios e familiares. Na vasta mesa montada sobre a relva, uma das características da cultura libanesa era expressamente vista: a presença abundante de variados pratos típicos, acompanhados do pão árabe, potes de coalhada, frutas e doces. Depois, os imigrantes fundaram os clubes libaneses que serviam, também, às necessidades locais de sociabilização devido à pouca presença da família no cotidiano do imigrante libanês.

A formação dos clubes sociais e, ainda, de hospitais, especialmente em grandes capitais brasileiras, sempre esteve determinada por uma característica dos imigrantes libaneses cristãos (GATTAZ, 2005; SAFADY, 1966.). Em São Paulo, por exemplo, onde houve grande fluxo imigratório, vários clubes, jornais e hospitais foram fundados graças à contribuição de membros da colônia libanesa. Já os libaneses muçulmanos preferiam fundar associações voltadas particularmente à divulgação e à prática islâmica. Segundo Truzzi (1997), a cidade de São Paulo foi a maior atração para estes imigrantes aventureiros, sendo 
considerada, pouco tempo depois, a maior cidade libanesa do mundo fora do Líbano, com quase dois milhões de libaneses e seus descendentes entre os seis milhões que residem no Brasil.

Entretanto, na convivência com os brasileiros, um fator conflitante que sempre causou desconforto para os imigrantes libaneses e descendentes diz respeito à questão histórica sobre sua identidade. $\mathrm{Na}$ época aproximada de 1960, antes referido, o império otomano exercia severo domínio sobre o Líbano e, por essa razão, qualquer indivíduo libanês que emigrava para outros países, era portador de passaporte fornecido por autoridades turcas. Independentemente de terem sua verdadeira procedência declarada, eles eram chamados de 'turcos', por ser a Turquia o país que lhes conferia permissão oficial para viagem. Qualquer imigrante oriundo de qualquer país árabe era chamado de 'turco', fosse egípcio, argelino, persa, palestino, sírio, libanês etc..

Segundo Wachowicz (1967), os imigrantes libaneses chegaram ao Paraná pelo desembarque nos portos de Paranaguá e Antonina, dirigindo-se, mais tarde, à capital Curitiba e a outras cidades do estado. De acordo com Sahão (1989), os libaneses (cristãos) chegaram ao Patrimônio Três Bocas, atualmente Londrina, a partir do ano de 1931, antes mesmo da fundação oficial do município (em 10 de dezembro de 1934). Conforme ocorreu nos demais lugares do Brasil, os imigrantes iniciaram o trabalho como mascates ambulantes, montados em cavalos e jumentos e, com o passar do tempo, participaram do processo de desenvolvimento da cidade, abrindo lojas nas ruas centrais da cidade, ampliando seus estabelecimentos e expandindo até as cidades vizinhas.

A participação expressiva dos libaneses na ocupação espacial e no povoamento de Londrina fez-se notar, com o passar do tempo, com a inserção de seus descendentes com formação profissional no país, possibilitando a atuação em posições de destaque na sociedade não apenas no comércio e indústria, mas também em distintos segmentos da área profissional. Associação (2004) apresenta uma relação detalhada da participação dos imigrantes libaneses na cidade, em diferentes áreas de atuação, desde o período de colonização até os dias atuais. $\mathrm{Na}$ medicina, por exemplo, o autor registra que o primeiro pediatra da cidade foi um filho de libanês, chegado em 1941, o qual fundou a associação médica da cidade, presidiu instituições de saúde e 
ensino superior, fundando, ainda, clubes e creches. Tomando como base o atual guia médico de Londrina, é possível encontrar nomes de vários descendentes de libaneses atuando como profissionais em diversas especialidades médicas na cidade. Também na vida pública do estado e do país se encontram diversos nomes representados, por exemplo, pela família Miguel Buffara, Richa, Hauly, etc., descendentes de libaneses que nasceram e residiram na cidade de Londrina.

Além da participação socioeconômica na cidade, os libaneses participam da manutenção da identidade cultural da comunidade libanesa a partir das instituições existentes no interior da colônia, isto é, a Mesquita Islâmica, o jornal Voz. Árabe e a escola de língua árabe.

\section{Interferências fonético-fonológicas}

\subsection{Metaplasmos}

Genericamente, o metaplasmo representa uma alteração intencional ou não do código, praticado pelos falantes nos diversos níveis gráfico, ortográfico e fonético. O conceito de metaplasmos perpassa o âmbito dos processos de alteração fonética por que passa uma língua no decorrer do tempo. Para Coutinho (1976), metaplasmos são as modificações fonéticas que sofrem as palavras na sua evolução. Essas alterações, do ponto de vista diacrônico, podem ser constatadas a partir da diversidade dos textos existentes, desde o latim vulgar até os dias atuais, nos quais se nota, também, a evolução da língua em todos os níveis da organização linguística. Entretanto, tais modificações "não se dão por acaso, não são produzidas pela moda ou capricho, mas obedecem a tendências naturais, a hábitos fonéticos espontâneos" (COUTINHO, 1976, p. 35).

Nessa perspectiva, Carvalho e Nascimento (1981, p. 35) definem metaplasmos como "as alterações que as palavras sofrem durante sua evolução do Latim para o português”. No entanto, é válido observar que o funcionamento desses processos fonéticos que operam mudanças nas línguas é o mesmo no momento sincrônico. Segundo os autores, os metaplasmos podem ocorrer de quatro maneiras distintas, quais sejam: por permuta, por aumento, por subtração e por transposição. 
A partir da descrição dos dados obtidos nas entrevistas, identificamos tipos distintos de metaplasmos, ${ }^{3}$ porém, nem todos constituíram interferências do árabe no português de contato produzido pelos informantes. Por exemplo, não foram considerados os casos de monotongação de ditongos [ai] > a, [ei] > e, [ou] > o; casos de ditongação de vogal mais sibilante, tais como em deiz $>$ dez, meis $>$ mês, paiz $>$ paz e outros, casos de iotização de [lh] $>$ [y], uma vez que esses fenômenos são traços característicos de variantes brasileiras do português e não representam casos específicos de interferência linguística. Observamos, portanto, que foram considerados somente os processos de alterações fonéticas de interferência ${ }^{4}$ ocorridos no português usado pelos falantes bilíngues envolvidos. Tendo em mente a exiguidade desse texto, apresentamos o fenômeno de sonorização da classe metaplasmos por permuta.

\subsection{Sonorização}

A sonorização consiste na permuta ou substituição de um fonema surdo por um fonema sonoro. Fonemas surdos são os que não apresentam vibração das pregas vocais quando produzidos. Por sua vez, seus pares homorgânicos /b/, /d/,/g/, /v/, /z/, /3/ são realizados com vibração das pregas vocais, sendo considerados, portanto, fonemas sonoros. Alguns pares de fonemas homorgânicos apresentam como característica o fato de se distinguirem pelo traço de sonoridade, isto é, alguns são surdos e outros são sonoros. Segundo Cristófaro-Silva (2009), uma consoante homorgânica é idêntica a outra em relação ao modo de articulação, à zona de articulação e ao papel das cavidades bucal e nasal, mas, diferente quanto à sonoridade, de forma que uma é surda e a outra, sonora. Com exceção de $/ \mathrm{J} /$, os

${ }^{3}$ Por ser este um trabalho pioneiro no que se refere à abordagem teóricometodológica, não é possível estabelecer comparação de dados com outros autores.

${ }^{4}$ Para a análise contrastiva dos sistemas fonético/fonológicos das línguas em questão, servimo-nos do trabalho de Jubram (2004), que estabelece quadros contrastivos da fonologia do árabe padrão e do português brasileiro, a fim de basear nossas reflexões nesse nível da análise. 
demais fonemas surdos nos interessam neste estudo, isto é, os fonemas $/ \mathrm{p} /, / \mathrm{t} /, / \mathrm{k} /, / \mathrm{f} /, / \mathrm{s} /$.

As trocas de fonemas sonoros/surdos são fenômenos comumente encontrados e facilmente perceptíveis na produção linguística de falantes que alternam simultaneamente o uso de duas ou mais línguas. Weinreich (1974) considera "interferência fônica" quando um falante bilíngue identifica um fonema do sistema secundário, isto é, da língua estrangeira, como um fonema do sistema primário, ou seja, da língua materna, e o reproduz conforme as regras deste sistema. Dito de outro modo, a interferência ocorre quando o bilíngue transfere sons do sistema da língua materna para o da língua estrangeira, originando uma confusão de sons. Trata-se, portanto, do modo como o bilíngue percebe e reproduz os sons das duas línguas.

As substituições fonêmicas produzidas pelo contato do português brasileiro com as línguas de imigrantes são causas para a geração de preconceito social e linguístico em várias comunidades bilíngues no país. No contato alemão-português, por exemplo, Schneider (2008) estuda as (des)sonorizações de consoantes surdas e sonoras de $[\mathrm{b}, \mathrm{d}, \mathrm{g}]$ - $[\mathrm{p}, \mathrm{t}, \mathrm{k}]$, em descendentes de primeira e segunda geração nas escolas de três comunidades do Rio Grande do Sul, a fim de pensar as concepções e o tratamento que os professores dispensam a esses traços linguísticos. Os resultados mostrados pela autora apontam para conflitos educacionais e identitários que são refletidos diretamente na vida educacional e social dos falantes. Por fim, a autora ressalta que as (des)sonorizações, assim como quaisquer outros traços de fala, não constituem um problema, mas o tratamento social que os falantes conferem a esses traços muitas vezes é problemático, quando, por exemplo, são utilizados como meios de discriminação social e linguística, mediante risadas, imitações, piadas e brincadeiras.

Em nosso corpus, encontramos tipos diversos de sonorizações que envolvem o mesmo ponto de articulação, em diferentes ambientes dos vocábulos. Dos casos registrados, o que envolve a troca de fonema $/ \mathrm{p} /$ por $/ \mathrm{b} /$, tratamos em particular, propositadamente, uma vez que esse fenômeno constitui um traço da fala dos informantes historicamente estigmatizado no Brasil, desde o início da imigração até os dias de hoje. Os demais casos de sonorização são considerados em conjunto, seguidamente. Para analisar a sonorização, tratamos separadamente as variáveis sociais das variáveis linguísticas. 
Considerando o número significativo de sonorizações de $[\mathrm{p}]>$ [b], apresentamos a tabulação dos dados, tratados com base na Sociolinguística Quantitativa, de acordo com as variáveis sociais envolvidas neste estudo: escolaridade, religião e gênero/sexo.

\subsubsection{Influência das variáveis sociais}

Quadro 1 - Distribuição numérica de sonorização de /p/ > /b/, por informante, segundo a variável escolaridade

\begin{tabular}{|c|c|c|c|c|c|c|c|c|c|c|c|c|c|c|c|c|c|}
\hline \multirow{4}{*}{$\begin{array}{l}\text { Sonorização } \\
/ \mathrm{p} />/ \mathrm{b} /\end{array}$} & \multicolumn{16}{|c|}{ Variável Escolaridade } & \\
\hline & \multirow{2}{*}{\multicolumn{8}{|c|}{$\begin{array}{c}\text { Ensino Fundamental } \\
\text { Informantes }\end{array}$}} & \multicolumn{8}{|c|}{ Ensino Médio } & \\
\hline & & & & & & & & & \multicolumn{8}{|c|}{ Informantes } & \\
\hline & \multicolumn{5}{|c|}{\begin{tabular}{|l|l|} 
& 5 \\
\end{tabular}} & & & 8 & 9 & 10 & 11 & 12 & 13 & 14 & 15 & 16 & Total \\
\hline Ocorrências & - & - & 4 & 4 & 3 & - & - & 5 & - & - & - & - & - & - & - & 26 & 42 \\
\hline Manutenção & - & - & 191 & 233 & 495 & - & - & 211 & - & - & - & - & - & - & - & 428 & 1600 \\
\hline
\end{tabular}

O quadro 1 traz os números de ocorrências da sonorização de [p] $>$ [b] e os de manutenção da surda. Do total de 1.600 ocorrências de contextos com a surda [p], 1.558 são registros dentro do português padrão e apenas 42 trazem a troca fonêmica, o que representa 97,4\% de formas sem interferência e apenas $2,6 \%$ de interferência. Esta sonorização se verifica entre 5 dos 16 informantes, sendo 4 do fundamental e um único do ensino médio. Embora o informante 16 demonstre o maior número de ocorrências de sonorização de [p] > [b], este fato fonético distribui-se na fala de 4 dos 8 informantes de nível fundamental.

Os dados apresentados indicam que o número de informantes com permutas de fonema /b/ em lugar de /p/ não é expressivo, tendo em mente o número total de entrevistados nos dois níveis. Ao contrário do que esperávamos, apenas $31,2 \%{ }^{5}$ dos participantes confundem os fonemas consonantais dos dois sistemas fonológicos; os outros $68,8 \%$ os utilizam segundo as normas do português. Um

${ }^{5}$ De início, observamos que as análises realizadas apresentam índices percentuais aproximados. 
aspecto significativo é indicado pela distância entre os altos índices de manutenção do uso de formas padrão, com fonema/p/, por informante, em relação ao baixo número de interferências, com o uso do /b/, antes mencionado. Verificamos que o informante 5, por exemplo, permutou os fonemas em apenas 3 palavras, mas, em outras 495 palavras, manteve a forma padrão surda. Portanto, os dados obtidos servem para levantarmos a hipótese de que a escolarização é fator responsável pela inibição do fenômeno na amostra coletada.

Por outro lado, há de se lembrar que o fato de os informantes com mais escolaridade perceberem e reproduzirem com mais clareza os sons sonoros e surdos possivelmente possa estar ligado ao conhecimento de mais de uma língua, isto é, o árabe e o francês. Os informantes estudaram em escolas públicas libanesas, onde o ensino do francês foi introduzido e padronizado pelo domínio político da França sobre o Líbano, desde 1920. A partir de então, a língua francesa mantém-se enraizada culturalmente no país até os dias atuais. Por sua vez, como língua românica, o francês possui vários traços que o aproxima do português, daí a facilidade de aprendizagem dessa língua, principalmente para aqueles informantes que frequentaram escolas por mais tempo.

Uma vez descritos os dados com base na variável escolaridade, testamos a variável religião, conforme mostra o quadro 2 .

Quadro 2 - Distribuição numérica de sonorização de [p] > [b] segundo a variável religião

\begin{tabular}{|c|c|c|c|c|c|c|c|c|c|c|c|c|c|c|c|c|}
\hline \multirow{4}{*}{$\begin{array}{l}\text { Sonorização } \\
/ \mathrm{b} />/ \mathrm{p} /\end{array}$} & \multicolumn{16}{|c|}{ Variável religião } \\
\hline & \multirow{2}{*}{\multicolumn{8}{|c|}{$\begin{array}{c}\text { Grupo Muçulmano } \\
\text { Informantes }\end{array}$}} & \multicolumn{8}{|c|}{ Grupo Cristão } \\
\hline & & & & & & & & & \multicolumn{8}{|c|}{ Informantes } \\
\hline & 3 & 4 & 7 & 8 & 11 & 12 & 15 & 16 & 1 & 2 & 5 & 6 & 9 & 10 & 13 & 14 \\
\hline Ocorrências & 4 & 4 & - & 5 & - & - & - & 26 & - & - & 3 & - & - & - & - & - \\
\hline Porcentagem & $2 \%$ & 1,7 & - & $2,4 \%$ & - & - & - & $5,7 \%$ & - & - & $0,6 \%$ & - & - & & - & - \\
\hline
\end{tabular}

Os resultados organizados no quadro 2 indicam o número de ocorrências de trocas fonêmicas de $/ \mathrm{p} />/ \mathrm{b} /$ e seus percentuais por informante. Do total de 16 informantes, observa-se um número de 39 ocorrências do fenômeno distribuídas na fala de 4 informantes do 
grupo muçulmano, representando $50 \%$ dos informantes dessa religião. Já no grupo cristão, há 3 ocorrências de sonorização vistas em apenas 1 informante, indicando um percentual de 12,5\% dos informantes deste grupo.

Os dados expostos sugerem uma nítida fronteira que coloca, de um lado, o grupo muçulmano com maior incidência de trocas fonêmicas de $/ \mathrm{p} />/ \mathrm{b} / \mathrm{e}$, de outro, o grupo cristão com menos incidência do fenômeno. Entre os muçulmanos, o informante 16, com maior ocorrência de interferências, tem especial status na comunidade, pois cumpriu recentemente o quinto pilar do islamismo, que ordena a peregrinação à cidade de Meca, para os fiéis que têm condições para isso. Com título honorífico de Haji, esse informante relatou-nos, durante a entrevista, os fundamentos da fé islâmica por meio da exposição detalhada dos deveres exigidos dos fiéis no cumprimento dos cinco pilares da religião. A obediência às regras, contudo, exige, obrigatoriamente, o uso do árabe clássico como um instrumento que garante a validade da prática islâmica, desenvolvida por meio do exercício de cinco orações diárias, das leituras, recitações de versos corânicos e outros.

Essas informações nos permitem considerar que a relação entre a variável religião e o fenômeno de sonorização de /b/ por /p/ deve ser vista a partir do intenso uso da língua árabe em função do cumprimento das leis islâmicas, por meio das quais os informantes são estimulados à prática religiosa.

Quadro 3 - Distribuição numérica de sonorização de /b/ > /p/ segundo a variável sexo/gênero

\begin{tabular}{|c|c|c|c|c|c|c|c|c|c|c|c|c|c|c|c|c|}
\hline \multirow{4}{*}{$\begin{array}{c}\text { Sonorização } \\
/ \mathrm{p} />/ \mathrm{b} /\end{array}$} & \multicolumn{16}{|c|}{ Variável Sexo/Gênero } \\
\hline & \multicolumn{8}{|c|}{ Mulheres } & \multicolumn{8}{|c|}{ Homens } \\
\hline & \multicolumn{8}{|c|}{ Informantes } & \multicolumn{8}{|c|}{ Informantes } \\
\hline & 2 & 4 & 6 & 8 & 10 & 12 & 14 & 16 & 1 & 3 & 5 & 7 & 9 & 11 & 13 & 15 \\
\hline Ocorrências & - & 4 & - & 5 & - & - & - & 26 & - & 4 & 3 & - & - & - & - & - \\
\hline Porcentagem & - & 1,7 & - & $2,4 \%$ & - & - & - & $5,7 \%$ & - & $2 \%$ & $0,6 \%$ & - & - & & - & - \\
\hline
\end{tabular}

Verificam-se, no quadro 3, os valores relativos às ocorrências da sonorização de formas de /b/ em lugar de /p/ e a porcentagem 
do fenômeno em cada informante. Do número total de 8 informantes em cada gênero, 3 mulheres trazem 35 sujeitos ou $83 \%$ das ocorrências de sonorização, e 2 homens apenas sete, ou 17\% das ocorrências na amostra. Considerando o total de 42 ocorrências, 26 incidem apenas na informante 16 , e as 16 ocorrências restantes dividem-se nos demais informantes dos dois sexos. Assim, nota-se o maior rendimento na adoção das formas estigmatizadas da surda /p/, entre os informantes do sexo feminino, em relação aos do sexo masculino.

O quadro 3 é revelador no sentido de reproduzir os efeitos que as características próprias ao contexto sociocultural dos informantes exercem sobre eles, nos dois gêneros, consequentemente, e concretizamse nas trocas fonêmicas. Nesse ambiente cultural, exige-se dos homens maior empenho no trabalho e, contrariamente, uma atuação feminina restrita aos deveres da casa, à família e à manutenção dos laços culturais. Estudos de historiadores dessa imigração no Brasil, como Gattaz (2005) e Safady (1989), entre outros, confirmam o fato de as mulheres libanesas, além de cumprirem suas atividades no lar, sempre auxiliarem nos negócios da família, porém, em funções que não exijam uma qualificação pessoal específica.

\subsubsection{Influência da variável linguística segundo o contexto fônico}

Considerando o número total de 42 registros de sonorizações de $/ \mathrm{p} />/ \mathrm{b} /$, verificamos que a sua incidência ocorre em contextos distintos das palavras, conforme apresentamos a seguir: 
Quadro 4 - Distribuição numérica e percentual de sonorização de / $\mathrm{p} />$ /b/ conforme os contextos CV e CCV na palavra

\begin{tabular}{|c|c|c|c|}
\hline \multicolumn{4}{|c|}{ Contextos da palavra de ocorrências de trocas fonêmicas de $[\mathrm{p}]>[\mathrm{b}]$} \\
\hline Contextos & $\mathrm{CV}$ & $\mathrm{CCV}$ & Total \\
\hline Ocorrências & 29 & 13 & 42 \\
\hline Porcentagem & $69 \%$ & $31 \%$ & $100 \%$ \\
\hline Exemplos & $\begin{array}{c}\text { bilares [pilares] } \\
\text { birigoso [pirigoso] } \\
\text { bequena pequena] } \\
\text { bensa [pensa] } \\
\text { borco [porco] } \\
\text { babai [papai] } \\
\text { bortuguês [português] } \\
\text { biligrino [pelegrino] } \\
\text { bidra [pedra] } \\
\text { bato [pato] } \\
\text { barte [parte] } \\
\text { borta [porta] } \\
\text { bissui [possui] } \\
\text { batriçio [patrício] etc. }\end{array}$ & $\begin{array}{c}\text { brimera [primeira] } \\
\text { breto [preto] } \\
\text { bronunça [pronúncia] } \\
\text { brimu [primo] } \\
\text { abrendi [aprende] } \\
\text { cumbri [cumpri] } \\
\text { combra [compra] } \\
\text { branta [planta] } \\
\text { cobrida [cumprida] } \\
\text { brigada [empregada] } \\
\text { bra [pra] etc. }\end{array}$ & \\
\hline
\end{tabular}

Os dados do quadro 4 demonstram a distribuição numérica e percentual das incidências de trocas fonêmicas de $/ \mathrm{b} />/ \mathrm{p} /$, de acordo com os contextos na palavra. Das 42 ocorrências do fenômeno, 29 recaem em contexto fônico representado por CV e 13 ocorrências em contexto CCV, perfazendo um índice de 69\% das ocorrências no primeiro caso e 31\% no segundo. A realização do fonema /b/ se dá com mais frequência na posição inicial da palavra, constituindo sílaba com a vogal na posição nuclear, porém, nos casos em que o /p/ incide sobre o contexto silábico de $\mathrm{CCV}$, observa-se uma baixa no número de ocorrências de /b/.

Se levarmos em conta os parâmetros de produção dos segmentos consonantais e vocálicos, segundo Cristófaro-Silva (2009), parece-nos razoável supor que a produção de um som consonantal seja mais facilmente realizada com um segmento vocálico do que com um segmento consonantal. Além desse parâmetro, no primeiro caso, ocorre a formação de um padrão silábico do tipo $\mathrm{CV}$, isto é, $\mathrm{C}$ consoante e V - vogal, em que a vogal é o núcleo da sílaba e sempre tem presença obrigatória, já as consoantes ocupam as partes periféricas.

Com base nesses resultados, supõe-se que o contexto fônico indicado como favorecedor das substituições de fonema /p/ pelo 
/b/ é o início da palavra, em uma estrutura silábica composta por consoante seguida de vogal. Por conter uma vogal, intui-se que esse ambiente seja mais fácil de produzir o som, do ponto vista articulatório, em comparação à sílaba formada por duas consoantes e uma vogal. Além disso, a produção dessas interferências é favorecida pela contiguidade dos dois segmentos consonantais compartilhando o ponto e o modo de articulação. A este aspecto de natureza articulatória somase outro de natureza sistêmica, ou seja, relacionado à estrutura do sistema fonológico das línguas. Conforme Jubran (2004), não há equivalência de vários segmentos fonológicos entre o árabe e o português; inclusive, o fonema /p/, do sistema fonológico português, inexiste no sistema fonológico árabe. Entretanto, um agravante nesse caso de trocas de /p/_/b/ é que as duas consoantes - $p$ e $b$ - constituem fonemas distintos no português brasileiro, uma vez que podem contrastar-se em ambiente idêntico e implicar mudança de significado nas palavras.

Este aporte nos permite compreender casos particulares de interferências cristalizadas na linguagem dos informantes libaneses, as quais geraram uma variante idiossincrásica e se transformaram em marcas sociolinguísticas nacionalmente estigmatizada pelos brasileiros. Entre as mais conhecidas, é possível citar palavras do tipo: brimo [primo], burtuguês [português], brununça [pronúncia], [bosto-imposto], boca [pouco], baga [paga], entre outras. Esses traços de fala foram divulgados e tomaram dimensão nacional devido à intensa interação entre os falantes e, principalmente, à ampla distribuição dos falantes no território brasileiro.

Além da influência da variável escolaridade no desempenho linguístico, confirmada pela baixa taxa da sonorização em pauta, os dados demonstrados na tabela 4, também, nos permitem intuir que existe uma tendência geral por parte dos informantes envolvidos, devido ao longo tempo de permanência no país, em acomodar-se aos sons do português brasileiro.

Paralelamente ao caso de sonorização de /p/_ / b/, encontramos outros com permutas de /f/_/v/, /t t_/d/, /s/_/z/ e $/ \mathrm{k} / \mathrm{g} /$, os quais evidenciaram baixo número de ocorrências, não apresentando um enviesamento significativo com as variáveis sociais consideradas neste estudo. Por essa razão, consideramos tais casos de sonorizações, em conjunto, conforme apresentamos a seguir: 
1. Sonorização de $/ \mathrm{f} />/ \mathrm{v} /($ fricativas surda/sonora $)=1$ ocorrência na fala do informante $1 \mathrm{PFM} \mathrm{-} \mathrm{vavor} \mathrm{[favor]}$

2. Sonorização /t/ > /d/ (lábio dentais surda/sonora): 1 ocorrência na fala do informante $2 \mathrm{PHC}$ - prádica [prática]

3. Sonorização /s/ > / z/ (fricativas surda/sonora): 1 ocorrência na fala do informante $2 \mathrm{PFM}$ - zabedoria [sabedoria]

4. Sonorização / k/ > /g/ (guturais surda/sonora): 2 ocorrências na fala do informante $1 \mathrm{SHM}$ - gunversá [conversar], gompra [compra].

Similarmente ao que ocorreu no caso de sonorização de /p/ > /b/, antes referido, o fator linguístico que contribui nas trocas de fonemas surdos / f, t, s, k, / para os sonoros /v, d, z, g/ deve-se à contiguidade existente entre esses fonemas, podendo, por consequência, intercambiar-se e gerar interferências, principalmente no desempenho linguístico de informantes que receberam pouca ou insuficiente instrução formal das duas línguas.

\section{Considerações finais}

Conforme temos apresentado, o universo de observação deste estudo é o português produzido por falantes do árabe, notadamente permeado por interferências de traços fonéticos devido ao uso alternado de duas línguas. A análise das interferências na fala, dos pontos de vista linguístico e extralinguístico, unida à história sociocultural da comunidade a que pertencem, sugere que os traços fonéticos/ fonológicos que caracterizam tal comunidade de fala advêm do contato intra e interlinguístico entre o português brasileiro e o árabe, os quais se solidificam na fala e subjazem, entre outros fatores:

a) à distância linguística entre o português e o árabe;

b) à ausência de acesso ao aprendizado formal do português brasileiro;

c) ao status do árabe para os falantes muçulmanos, o qual deriva de sua íntima relação com a prática islâmica e, para os falantes 
cristãos, origina de sua importância como língua de cultura e tradição.

No estudo das sonorizações verificamos que, embora existam lacunas entre os sistemas fonológicos das duas línguas, as alterações fonéticas na pronúncia do português são inconscientes por serem alheias à vontade dos falantes e, também, aliam-se aos princípios de leis fonéticas das línguas, como, por exemplo, a lei do menor esforço, tendência universal em que o falante simplifica a emissão dos sons, facilitando aos órgãos do aparelho fonador. Nessa esteira, entre as estratégias usadas pelos informantes para aliviar a carga cognitiva de ter de lembrar e usar alternadamente dois sistemas fonológicos, deparamos com as trocas de fonemas surdos por sonoros.

Face às observações apresentadas acima, propomos, portanto, que as interferências da fala dos informantes desse estudo não sejam vistas como "erros", nem sejam usadas como instrumentos de estigmatização e intolerância, conforme prevê Weinreich (1953), mas, valorizadas como estratégias de cognição usadas pelos falantes como instrumentos de comunicação e interação com seus semelhantes. E, ainda, que as interferências sejam consideradas marcas identificadoras de membros de uma comunidade de fala que compartilha os mesmos traços linguísticos e lhes atribui valores positivos.

\section{Referências}

ASSOCIAÇÃO PRÓ-MEMÓRIA DE LONDRINA. Londrina Paraná Brasil: raízes e dados históricos. Londrina: Humanidades, 2004.

DURÃO, Adja Balbino de Amorim Barbieri. La interlengua. Cadernos de Didática del Español/LE. Madrid: Arco/Libros, 2007.

CARVALHO, Dolores G.; NASCIMENTO, M. Gramática histórica. São Paulo: Ática, 1981.

COUTINHO, Ismael de Lima. Pontos de gramática histórica. 7. ed. Rio de Janeiro: Livro Técnico, 1976. 
CRISTÓFARO-SILVA, Thaïs. A fonética do português brasileiro. Contexto: São Paulo, 2009.

FAERCH, Claus; KASPER, Gabriele. Perspectives on language transfer. Applied Linguistic, v. 8, n. 2, p. 111-136, 1987.

GATTAZ, André. Do Líbano ao Brasil: história oral de imigrantes. São Paulo: Gandalf, 2005.

GÓMES MOLINA, José R. Transferencia y cambio de código en una comunidad bilingüe Área metropolitana de Valencia (I y II). Contextos XVII-XVII, n. 33-36, p. 309-360, 1999-2000. Disponível em: <http: //www3.unileon.es/dp/dfh/ctx/1999-2000/Molina1.pdf>. Acesso em: 10 jan. 2008.

JUBRAN, S. A. A. C. Árabe e português: fonologia contrastiva. São Paulo: Humanitas, 2004.

KELLEMANN, E. The problem with difficulty. Interlanguage Studies. Bulletins, v. 4, p. 27-48, 1979.

KNOWLTON, Clark. S. Sirios e libaneses: modalidade social e espacial. São Paulo: Anhambi, 1995.

LABOV, William. On the grammaticality of everday speech. Paper givem at the Annual Meeting of the Society of America. New York City, Dec. 1966.

LADO, Robert. Introdução à lingüistica aplicada. Trad. Vicente Pereira de Souza. Petrópolis: Vozes, 1971.

MACKEY, Willian. Bilinguisme et contat des langues. Paris: Klincksieck, 1965.

MORENO FERNÁNDEZ, Francisco. Lenguas en contacto. In: - (Org.). Princípios del sociolinguística y sociologia del lenguaje. Barcelona: Ariel, 1998. p. 265-275.

MYERS-SCOTTON, Carol. Multiple voices: a introduction to bilingualism. Blackwel Publishing: Oxford, 2006. 
SCHERRE, Marta Maria P. et al. (Orgs.). Padrões sociolinguísticos. Rio de Janeiro: Tempo Brasileiro, 1996.

POULISSE, Nanda; BONGAERTS Theo. First language use in second language production. Applied Linguistic, n. 15, v. 1, p. 36-57, 1994.

SAFADY, Wadih. Cenas e cenários dos caminhos de minha vida: depoimento e contribuição para o estudo da imigração árabe no Brasil. Belo Horizonte: Estabelecimentos Gráficos Santa Maria, 1966.

SAFADY, Jorge. A imigração árabe no Brasil: 1880-1970. São Paulo: Garatuja, 1994.

SAHÃO, Sônia. Salim Sahão meu avô. Londrina: Cotação, 1989.

SELINKER, Larry; GASS, Susan M. Language transfer in language learning. Massachusetts: Newbury House Publishers, 1983.

SÁNCHEZ, Eulálio Fernández. Transferencias e interferencias en el aprendizaje de una segunda lengua. Encuentro - Revista de Investigación e Innovación en la clase de idiomas, Universidad de Córdoba, p. 106112, 1999-2000.

SILVA NETO, Serafim da. História da língua portuguesa. Rio de Janeiro: Presença, 1988.

SILVA-CORVALÁN, Carmen. Sociolinguística: teoria y análisis. Madrid: Alhamba Universidad, 1998.

SCHNEIDER, Maria Nilse. As (des)sonorizações e a neutralização da vibrante: atitudes e concepções lingüísticas. Contingentia, v. 3, n. 2, p. 77 88, nov. 2008.

TRUZZI, Oswaldo. Patrícios: sírios e libaneses em São Paulo. São Paulo: Hucitec, 1997.

HEYE, Jürgen; VANDRESEN, Paulino. Línguas em contato. In: CARDOSO, S.A.M.; MOTA, J.A.; MATTOS e SILVA, R.V. (Orgs.). 
Quinhentos anos de história linguística do Brasil. Salvador: Secretaria da Cultura e Turismo do Estado da Bahia, 2006. p. 383 - 411.

WEINREICH, Uriel. Languages in contact: finding and problems. New York: Linguistic Circle of New York, 1974.

WACHOWviZ, R. C. História do Paraná. Curitiba: Editora dos Professores, 1967. 